\title{
COMO DECIDEM OS JUÍZES? COMPARANDO OS MODELOS FORMAIS EXPLICATIVOS DO COMPORTAMENTO JUDICIAL
}

\section{HOW JUDGES DECIDES? COMPARING THE JUDICIAL BEHAVIOR FORMAL RESEARCH MODELS}

JOSÉ MÁRIO WANDERLEY GOMES NETO ${ }^{1}$

Resumo: Como decidem os juízes? Modelos formais de pesquisa são desenvolvidos e aplicados para permitir a interpretação de dados empíricos sobre os fenômenos concretos e a explicação destes fenômenos, mediante rígidas regras de inferência. São utilizados porque exercem o papel de realizar a interseção entre a teoria pura e os instrumentos metodológicos, sistematizando as informações colhidas e testando hipóteses relacionadas ao objeto de estudo, permitindo que pesquisas empíricas possam alcançar o conhecimento acerca de relações de causalidade entre diversas variáveis e o fenômeno factual que se pretende entender, in casu, as razões pelas quais há variação nas decisões judiciais. Os três modelos formais compilados neste trabalho oferecem explicações testáveis sobre o comportamento judicial, instruídos por variáveis que relacionam o resultado das decisões individuais ou coletivas a categorias jurídicas (legalista), a características prévias do julgador (atitudinal) e/ou à influência de outros atores ou de fatores externos ao Tribunal (estratégico). Este artigo realiza revisão sistemática dos referidos modelos, comparando suas características, de forma a auxiliar os leitores que desejem estudar empiricamente as decisões judiciais.

PalaVRas-ChaVe: Judicialização da política; Controle de constitucionalidade; Revisão judicial; Modelos explicativos.

1 Professor na Universidade Católica de Pernambuco. Doutor em Ciência Política pela UFPE. Contato: josemwgomes@gmail.com. 
Abstract: How do judges decide? Formal research models are developed and applied to allow the interpretation of empirical data about concrete phenomena and the explanation of these phenomena through strict rules of inference. They are used because they play the role of intersecting pure theory and methodological instruments, systematizing the information gathered and testing hypotheses related to the object of study, allowing empirical research to reach knowledge about causal relationships between several variables and factual phenomenon that is intended to understand, in casu, the reasons for which there is variation in court decisions. The three formal models compiled in this paper offer testable explanations of judicial behavior, instructed by variables that relate the outcome of individual or collective decisions to legal categories (legalistic), the judge's prior characteristics (attitudinal), and / or the influence of other actors. or factors external to the Court (strategic). This article systematically reviews these models, comparing their characteristics, in order to help readers to study empirically court decisions.

KEYWORDS: Judicial review, Explanatory models, Decision-making.

For the rational study of the law, the blackletter man may be the man of the present, but the man of the future is the man of statistics and the master of economics. - Oliver Wendell Holmes

\section{INTRODUÇÃO}

Como explicar empiricamente a variação verificada nas decisões judiciais? Nas poliarquias contemporâneas onde as relações entre as instituições formais e os indivíduos passam a ser previamente tuteladas por um detalhado texto constitucional, tem-se cenário favorável a um papel mais ativo dos Tribunais: um núcleo de direitos fundamentais e de princípios a serem respeitados pelo Administrador Público e um conjunto de garantias que asseguram uma relativa autonomia e independência dos membros do Poder Judiciário (DAHL, 1957; 1973; WEINGAST, 1997; BOBBIO, 2004; ELSTER, 1979; 2000).

Os órgãos judiciais não mais se limitam à resolução de conflitos individuais ou de questões eminentemente privadas, avançando sobre o ambiente público e ocupando lugares tradicionalmente reservados a instituições políticas majoritárias, sem que isto signifique um projeto com ambições de poder do Judiciário (TATE; VALLINDER, 1995).

A tradicional concepção de neutralidade judicial e de não interferência entre os Poderes constituídos do Estado é então questionada e submetida à revisão, diante dos fatos que atestam uma dinâmica de interação entre as instituições, pois o 
cenário demonstra uma aplicação mais frequente dos mecanismos institucionais de freios e contrapesos recíprocos.

Os Tribunais e demais instituições judiciais, pelo mundo inteiro, nunca tiveram papéis tão relevantes em relação aos assuntos governamentais (MURPHY et al., 2002). O processo decisório relativo à resolução de conflitos de natureza pública passa a se mesclar com o próprio processo de definição e de implementação de políticas públicas, passando a integrar o cálculo dos governantes, acompanhado de suas próprias preferências, de seus eleitores, dos parlamentares e demais grupos envolvidos na arena política (DAHL, 1957; WEINGAST, 1997; BOBBIO, 2004; GINSBURG, 2003; HIRSCH, 2004). Nesse contexto, surge o fenômeno sócio-político da judicialização da política.

Fatores explicativos para a ocorrência desta parcela do fenômeno, uma vez identificadas condições favoráveis, estão agrupados em duas dimensões analíticas: uma, centrada na racionalidade dos atores políticos responsáveis por iniciar a judicialização de uma questão política (input); outra, situada em momento posterior, pautada pela racionalidade adotada pelos juízes, individual ou coletivamente, para a decisão dos mencionados casos (output).

No âmbito desta segunda dimensão de pesquisa, surgem os modelos formais como relevantes instrumentos voltados a permitir a interpretação de dados empíricos sobre os fenômenos concretos e a explicação destes fenômenos, mediante rígidas regras de inferência. Os três modelos formais compilados neste trabalho oferecem explicações testáveis sobre o comportamento judicial, instruídos por variáveis que relacionam o resultado das decisões individuais ou coletivas a categorias jurídicas (legalista), a características prévias do julgador (atitudinal) e/ou à influência de outros atores ou de fatores externos ao Tribunal (estratégico).

Este artigo realiza revisão sistemática dos referidos modelos, comparando suas características, de forma a auxiliar os leitores que desejem estudar empiricamente as decisões judiciais.

\section{MODELOS CAUSAIS E COMPORTAMENTO DOS ÓRGÃOS JUDICIAIS}

Todos os modelos mencionados têm em comum a apresentação, individual ou conjunta, de elementos que se propõem a explicar os motivos pelos quais as decisões dos órgãos judiciários são tomadas, a serem confirmados através de testes empíricos aplicados sobre dados relacionados às referidas decisões.

[A] causalidade é uma propriedade de um modelo hipotético. Um modelo totalmente articulado dos fenômenos estudados precisamente define estados hipotéticos ou contrafactuais. [...] Um modelo é um conjunto de mundos possíveis contrafactuais construídos sob algumas regras. As regras podem ser as leis da física, as consequências da maximização da utilidade, ou as normas 
que regem as interações sociais, para tomar apenas três dos muitos exemplos possíveis. (HECKMAN, 2005, p. 02)

Um modelo causal em ciências sociais (Sociologia, Ciência Política, Direito etc.) consiste na articulação de uma série de variáveis, premissas e equações, tomadas como representações numéricas, ordinais ou categóricas de aspectos de um fato ou de um fenômeno, utilizada como ferramenta para capturar a essência de um comportamento e explicar os processos intrínsecos à sua ocorrência (NAGEL; NEEF, 1977).

Um modelo consiste numa representação simplificada da realidade; não se trata da realidade em si. Modelos propositadamente ignoram certos aspectos da realidade e, em contrapartida, focam em selecionados, às vezes até relacionados, conjuntos de fatores cruciais. Está simplificação fornece um instrumento útil a um entendimento do mundo real que estudos mais exaustivos e descritivos não alcançam (SEGAL; SPAETH, 2002, p. 45, destaquei).

Cientistas sociais em geral, incluindo cientistas políticos, partem da teoria para gerar implicações observáveis e então aplicar procedimentos transparentes para inferir a partir de dados se a teoria se aplica ao fenômeno social analisado. Os modelos fazem a ponte entre a teoria pura e os instrumentos metodológicos, sistematizando as informações colhidas e testando hipóteses relacionadas ao objeto de estudo (KING; KEOHANE; VERBA, 1995).

Trabalhos teóricos e empíricos, a partir desta perspectiva, não podem produtivamente existir em isolamento uns dos outros. Acreditamos que isso pode se tornar um procedimento padrão, de modo a demandar implicações claras da teoria e verificações observacionais destas implicações, obtidas a partir de um método que minimize os vieses (KING; KEOHANE; VERBA, 1995, p. 476).

Modelos formais de pesquisa são desenvolvidos e aplicados para permitir a interpretação de dados empíricos sobre os fenômenos e a explicação destes fenômenos, mediante rígidas regras de inferência.

Os concorrentes modelos de comportamento judicial diferem sobre uma série de questões, que vão desde o lugar de direito ao julgar à influência do público na Suprema Corte. Grande parte dos estudiosos desta área centra-se nestas diferenças, a exemplo de 
estudiosos que defendem posições específicas e realizam pesquisas sobre pontos de discordância entre os modelos. (BAUM, 2009, p. 09)

Tais modelos explicativos do comportamento judicial existem enquanto ferramentas epistemológicas para "deduzir predições do que irá ocorrer se houver alguma alteração nos inputs ou deduzir prescrições do que pode acontecer diante de determinados outputs previstos" (NAGEL; NEEF, 1977, p. ix).

Para que se converta em conhecimento sobre um dado tribunal, a produção de dados sobre votos dos juízes, perfis dos processos ingressantes no tribunal e resultados de julgamentos precisa ser acoplada a perspectivas teóricas sobre as próprias instituições judiciais que nos permitam interpretar esses inputs empíricos. Isso porque o mesmo conjunto de dados pode sustentar diferentes descrições e explicações sobre como os juízes em uma dada instituição judicial chegaram àqueles resultados. (RIBEIRO; ARGUELHES, 2013, p. 88)

As premissas inerentes ao modelo permitem aos analistas interpretar as nuances sobre determinado fenômeno do comportamento judicial, $v . g$., decisões em controle concentrado de constitucionalidade ou concessões de liminares contra o Poder Público, a partir de testes de suas hipóteses, operados pela submissão de dados do fato investigado a ferramentas estatísticas de análise causal. Entretanto, não se limitam a predições baseadas em probabilidade, mas também oferecem interessantes esclarecimentos sobre os fatores que influenciam na variação de comportamento dos órgãos judiciais.

[...] [P]recisamos mais do que predição; precisamos de explicações. O modelo jurídico-normativo [legalista], o modelo atitudinal e o modelo de separação de poderes [estratégico ou de escolha racional] dirigem-se todos a prover explicações acerca do que o Tribunal realmente faz. (SEGAL; SPAETH, 2002, p. 351)

Neste trabalho, a partir de então, serão apresentados, em conjunto, os três principais e mais utilizados modelos teóricos explicativos do comportamento judiciário - o legalista, o atitudinal e o estratégico.

Uma crescente literatura busca sistematicamente examinar os juízes e suas decisões jurídicas. Tendo em conta que os juízes muitas vezes desempenham um papel crítico em nossas vidas constitucionais, políticas, econômicas e sociais, é evidente que precisamos de uma melhor compreensão de como e por que os juízes chegam às suas 
decisões, tomadas no decurso do exercício de suas funções judiciais. (HEISE, 2002, p. 832)

Serão investigadas suas semelhanças e dessemelhanças, bem como as hipóteses e variáveis inerentes a cada modelo, trazendo, ao final de cada item, uma revisão de relevantes trabalhos publicados na literatura estrangeira e brasileira, que se utilizaram dos referidos modelos para explicar empiricamente problemas de pesquisa relacionados a decisões judiciais.

\section{O MODELO LEGALISTA}

Estimar precisamente o que a lei "diz" sobre o caso objeto do conflito, todavia, é uma tarefa bastante difícil, levando os estudiosos a testar o modelo legalista a partir do exame das decisões em relação aos precedentes judiciais que examinaram questões idênticas ou semelhantes, ou, ao menos, identificar categorias jurídicas a serem empregadas com o propósito de controlar o modelo, a partir de regras jurídicas semelhantes que possam ser aplicadas a estes casos. Estas categorias e respectivos casos podem ser observadas em Segal e Spaeth (2002).

Em primeiro lugar, o modelo legalista vê o ato de julgar como uma atividade puramente neutra e técnica, isto é, para esta concepção, juízes decidem casos baseados estritamente naquilo que está escrito na lei, bem como nos princípios, nos precedentes e nas demais fontes jurídicas.

Será que as normas jurídicas influenciam no processo decisório judicial? Muitos pesquisadores, nas faculdades de Direito e por todos os lugares, passam bastante tempo revisando, categorizando e vinculando textos jurídicos. Eles assumem que, a partir do conhecimento de várias regras, princípios e estruturas argumentativas, estarão em melhor posição para compreender um largo alcance de relações sociais e práticas políticas, incluindo porque os juizes decidem os casos das maneiras como fazem. (GILMANN, 2001, destaquei)

Para Baum (2009), a concepção de juízes adotada por esse modelo procura apenas buscar o "bom direito", ou seja, procura interpretar as leis cuidadosamente, sem se preocupar com a aceitação pelos grupos destinatários das novas políticas públicas ou modificações nas políticas públicas existentes, que possam ter origem nas suas decisões, ao julgar conflitos envolvendo direito público e questões politicamente relevantes.

Em outras palavras, este juiz [objeto do modelo legalista] procura interpretar a norma com precisão, sem preocupação com a conveniência das políticas que possam daí resultar. Diante de um 
caso sobre liberdade de expressão [por exemplo], o juiz legalista simplesmente procuraria qual a melhor interpretação da Primeira Emenda. (BAUM, 2009, p. 08)

Os modelos legalistas não admitem que outros fatores (como ideologia ou filiação partidária) possam afetar a maneira como os Tribunais constroem suas decisões, sugerindo, em sentido contrário, que os juízes excluem espontaneamente quaisquer vieses pessoais ou políticos na elaboração de suas decisões (EPSTEIN; WALKER, 2007, p. 37).

Para esses estudiosos, decisões judiciais foram atos políticos não porque os juízes eram como os policymakers eleitos, que conscientemente avançam suas preferências políticas ou interesses constituintes, mas porque a própria lei era um processo para a construção de valores políticos e a interpretação jurídica foi sempre influenciada por forças políticas profundas que moldaram as atitudes judiciais em níveis de efetividade e cognição. Esses estudiosos também reconhecem que esta concepção constitutiva da relação entre direito e política exige uma necessária vinculação entre a análise descritiva da doutrina e das instituições jurídicas e a análise política normativa. (CLAYTON, 1999, p. 21)

Este modelo sugere a existência de relativa estabilidade nas decisões que analisam hipóteses de controle judicial de legalidade ou de inconstitucionalidade (judicial review), não havendo mudança significativa na trajetória dos julgamentos, salvo diante de alterações na Constituição, na legislação ordinária ou nos precedentes, ocorridas antes do caso em questão (MALTZMAN et al., 1999). Os membros do Tribunal, para o modelo legalista, não podem seguir suas próprias preferências pessoais, os desejos do público ou outros fatores relevantes e nãojurídicos, se quiserem manter o respeito de seus colegas e do restante da comunidade jurídica (MALTZMAN et al., 1999, p. 25).

Num modelo legalista puro, assume-se que os juízes apenas querem interpretar a lei da melhor maneira possível. Por esta razão, eles escolhem entre os resultados para os casos e/ou posições doutrinárias alternativos, baseados nos respectivos méritos jurídicos (BAUM, 2009, p. 05), ou seja, espera-se que o comportamento judicial seja pautado pela maneira como o órgão julgador (individual ou coletivo) reage às fontes do direito (a legislação, os precedentes, os costumes jurídicos, os princípios, a literatura jurídica etc.).

Estreicher e Sexton (1986) aplicaram um modelo legalista para explicar a concessão do writ of certiorari, isto é, a inclusão, ou não, pela Suprema Corte norteamericana de determinados conflitos na sua agenda de julgamentos: para eles, os membros daquela Corte teriam uma concepção uniforme quanto aos temas que 
deveriam, ou não serem julgados e os resultados binários aceitação (Significant) ou rejeição (Nonsignificant) - quanto à apreciação de um caso - estariam condicionados à presença ou à ausência de variáveis que representariam o enquadramento dos conflitos em uma entre três categorias (prioritários, discricionários ou improcedentes), sendo aqueles incluídos na primeira categoria com maiores chances de sua apreciação pela Corte, o que reforçaria a ideia de independência dos Justices na formação da agenda (ESTREICHER; SEXTON, 1986; COOK, 1994).

Segal (1984) utilizou o modelo legalista para demonstrar a existência de um padrão decisório na Suprema Corte norte-americana, nos casos envolvendo a aplicação da $4^{\text {a }}$ Emenda à Constituição, com satisfatórios resultados explicativos e preditivos.

Johnson (1987), por sua vez, estudando o grau de fidelização dos Tribunais Federais aos precedentes da Suprema Corte estadunidense, aplicou o modelo legalista e encontrou correlações que apontavam para interessante comportamento: uma maior fidelização aos precedentes que tratavam de casos mais complexos e uma menor fidelização aos precedentes relativos a conflitos de menor complexidade, assim considerados a partir de variáveis para clareza e complexidade, extraídas de estudos anteriores que categorizam os precedentes pela metodologia de painéis.

Outro trabalho (SEGAL; SPAETH, 2002) utilizou a explicação legalista para demonstrar as circunstâncias em que a Suprema Corte norte-americana seria mais propícia a revogar, total ou parcialmente, seus próprios precedentes (em contraponto ao desenho institucional e ao sistema stare decisis de vinculação aos precedentes), como forma de ilustrar as próprias limitações do modelo em comparação com as explicações estratégicas e atitudinais.

Tem-se exemplo semelhante em relação ao caso brasileiro: com o propósito de analisar quais fatores influenciavam no deferimento de medidas liminares em ações diretas de inconstitucionalidade (ADINs) pelo Supremo Tribunal Federal, Taylor (2008) empregou o modelo legalista para testar eventuais associações com as variáveis jurídicas enquadradas nas categorias tópico (relacionando o assunto objeto do conflito, p.ex., reforma da previdência social, regulação econômica, orçamento etc.) e espécie normativa (assumindo que o tipo da legislação teria influência na possibilidade de sucesso na revisão constitucional, v.g., Emendas Constitucionais, medidas provisórias, leis ordinárias, decretos etc.).

Na categoria tópico, o modelo legalista foi capaz de demonstrar que o assunto tratado exercia influência sobre o deferimento das liminares, especialmente quando a legislação tratava de benefícios do próprio Judiciário e de questões fiscais e tributárias, enquanto que na categoria espécie normativa, a despeito de ser intuitivamente hipótese forte para a concessão de liminares, o modelo mostrou uma influência muito sutil nas decisões dos Ministros do STF (TAYLOR, 2008, p. 82-84).

Por outro lado, o modelo legalista também foi testado em outra situação: na explicação das decisões individuais tomadas pelos sucessivos Ministros 
Presidentes do Supremo Tribunal Federal, quando provocados a decidir os instrumentos chamados pedidos de suspensão ${ }^{2}$, em hipóteses em que uma dentre as pessoas jurídicas de direito público ou o ministério público requer a suspensão dos efeitos concretos de uma decisão judicial proferida por órgão judicial situado em nível hierárquico inferior, quando supostamente capaz de produzir dano à ordem, à economia, à saúde ou à segurança públicas (Fundamentos para propor, i.e., provável lesão à ordem pública ou à economia pública, e Matéria objeto do conflito, i.e., tributário ou previdenciário), todas variáveis legalistas, não apresentaram nenhuma relação causal sobre a possibilidade de deferimento da medida (GOMES NETO, 2015).

Uma crítica presente na literatura quanto ao modelo legalista é que este falharia ao não prover um ambiente no qual a atividade judicial fosse relacionada com o comportamento dos demais Poderes do Estado, deixando de submeter as instituições judiciais e seus processos decisórios às mesmas ferramentas utilizadas para descrever e entender os processos decisórios realizados no âmbito das outras instituições governamentais (PRITCHETT, 1968).

Em suma, assume-se, nas investigações que empregam o modelo legalista, a concepção testável que as normas jurídicas e precedentes judiciais, bem como suas características e conteúdos, importam para a maneira como os casos serão decididos pelos juízes, seja individualmente, seja por meio dos órgãos colegiados (GILMANN, 2001).

Entretanto, do ponto de vista empírico, seria ingênuo afirmar que apenas fatores legalistas seriam capazes de produzir efeitos sobre as decisões judiciais (individuais ou coletivas), negando ou omitindo o papel desempenhado pelas preferências dos juízes nos processos decisórios. Para as situações em que os fatores legalistas (isoladamente) pouco ou nada explicam sobre a variação decisória judicial surgem oportunidades para o uso de modelos atitudinais e/ou estratégicos.

2 Este instrumento recebe várias denominações - suspensão de segurança, suspensão de liminar, suspensão de tutela antecipada etc e sua utilização está prevista nas seguintes normas processuais: art.25 da Lei no 8.038/90; art. $4^{\mathrm{o}}$ da Lei n⿳o 8.437/92; e art.15 da Lei $\mathrm{n}^{\mathrm{o}}$ 12.016/09. 
Quadro 1 - Modelo Legalista

\begin{tabular}{|c|c|c|c|c|}
\hline Modelo & Hipóteses & Variáveis mais utilizadas & Referências & Ferramentas de pesquisa frequentes \\
\hline LEGALISTA & $\begin{array}{l}\text { Somente fatores jurídicos (leis, princípios } \\
\text { fundamentais, jurisprudência, doutrina etc.) } \\
\text { influenciam nas decisões judiciais. } \\
\text { Vê o ato de julgar como uma atividade } \\
\text { puramente neutra e técnica, isto é, para esta } \\
\text { concepção, juizes decidem casos baseados } \\
\text { estritamente naquilo que está escrito na lei, } \\
\text { bem como nos princípios, nos precedentes e } \\
\text { nas demais fontes jurídicas. } \\
\text { Os membros da Corte, para o modelo legalista, } \\
\text { não podem seguir sua próprias preferências } \\
\text { pessoais, os desejos do público ou outros } \\
\text { fatores relevantes e não-jurídicos, se quiserem } \\
\text { manter o respeito de seus colegas e do restante } \\
\text { da comunidade jurídica }\end{array}$ & $\begin{array}{l}\text { Espécie normativa (Constituição, leis } \\
\text { complementares, leis ordinárias, medidas } \\
\text { provisórias, Códigos, decretos, portarias etc.) } \\
\text { Competência da norma } \\
\text { (federal, estadual, distrital ou municipal). } \\
\text { Matéria objeto do conflito (previdenciário, } \\
\text { tributário, licitações, servidores públicos, } \\
\text { contratos, direitos fundamentais etc.) } \\
\text { Fonte do Direito utilizada na decisão } \\
\text { (legislação, precedentes jurisprudenciais, } \\
\text { doutrina, principios etc.) }\end{array}$ & $\begin{array}{l}\text { Estreicher e Sexton } \\
(1986) \\
\text { Segal (1984) } \\
\text { Johnson (1987) } \\
\text { Segal e Spaeth } \\
(2002) \\
\text { Taylor (2008) }\end{array}$ & $\begin{array}{l}\text { Estatística descritiva } \\
\text { Análise de clusters } \\
\text { Análise por regressão logística (Logit) } \\
\text { Análise por regressão multinominal } \\
\text { Análise de sobrevivência } \\
\text { Análise fatorial } \\
\text { QCA }\end{array}$ \\
\hline
\end{tabular}

Fonte: Elaboração do autor.

\section{O MODELO ATITUDINAL}

Em segundo lugar, o modelo atitudinal considera que as preferências (v.g., políticas) individuais de cada juiz influenciam no processo de elaboração das decisões judiciais. A legislação é frequentemente vaga, ambígua e excessivamente vulnerável a várias interpretações divergentes, o que leva os atitudinalistas a afirmarem que são, na verdade, os valores, crenças e/ou atitudes políticas dos juízes que explicam a variação nos resultados das decisões judiciais.

Para os atitudinalistas (SEGAL; SPAETH, 2002, p. 85), no que diz respeito à pauta das decisões judiciais, trata-se de deixar o mundo ideal e abstrato das leis, dos precedentes e da história para se adentrar no mundo concreto das atitudes e dos valores.

Uma visão predominante, senão não for aquela predominante, acerca do processo decisório judicial na Suprema Corte Norte-Americana é o modelo atitudinal. Este supõe que os valores ideológicos dos magistrados proporcionam os melhores indicadores do resultado de seus votos. (SEGAL et al., 1995, p. 812)

Os atitudinalistas costumam conceber as atitudes judiciais como preferências políticas quantificáveis que podem ser categorizadas e arranjadas matematicamente ao longo de uma escala convencional entre "liberais" ou "conservadores", ou entre "direita" ou "esquerda" (GILLMAN, 2001).

Apresentada essa corrente de outra maneira, os atitudinalistas explicam a presença de orientação política nas decisões a partir dos valores e ideologias de cada juiz (CLAYTON, 1999), v.g., considerando que os juízes decidem os casos à 
luz de seus sinceros valores ideológicos justapostos aos estímulos fáticos de cada caso (SEGAL, 2008, p. 24).

Poucos esforços são realizados no sentido de explorar se as normas ou contextos institucionais produzem um efeito independente nas atitudes dos magistrados ou na sua habilidade de favorecer suas condutas preferidas, possivelmente porque os adeptos da utilização deste modelo de pesquisa assumem que a referência aos efeitos institucionais independentes é desnecessária, dada a suficiência das explicações atitudinais para demonstrar correlações entre as preferências políticas individuais e o comportamento judicial verificado na elaboração de seus votos (GILMAN; CLAYTON, 1999).

"Se os juízes não são legalistas, o que são? Seriam simplesmente políticos togados?"(POSNER, 2008, p. 08). Muitas decisões judiciais, conforme demonstram estudos de natureza empírica, ainda que limitadas pelos precedentes da Suprema Corte, são fortemente influenciadas pelas preferências políticas de cada juiz, que se refletem nos resultados e nos fundamentos de cada julgamento. Num modelo atitudinal puro, os juízes apenas querem produzir boas políticas públicas, então escolhem entre alternativas com base nos seus méritos como política pública (BAUM, 2009, p. 05).

Neste sentido, qual seria a importância das categorias ideológicas utilizadas para descrever o comportamento e as decisões dos juízes? Oferecer predições acuradas sobre o comportamento judicial futuro, se mantido o ambiente institucional e contexto político (EPSTEIN; WALKER, 2007).

O modelo atitudinal parte do princípio de que as decisões judiciais podem ser explicadas a partir das preferências políticas que os julgadores trazem para análise dos conflitos, inferindo tais preferências a partir de variáveis indiretas (POSNER, 2008, p. 19-20), a exemplo dos interesses específicos e/ou conteúdo programático do partido político a que está filiado o Presidente que indicou o operador do direito (juiz, membro do Ministério Público, advogado ou professor universitário) para o cargo de Ministro do Supremo Tribunal Federal ou de Justice da Suprema Corte norte-americana (GOMES NETO, 2012, p. 109).

Na literatura sobre o tema dos processos decisórios, seja comparativa ou norteamericana, estas atitudes são frequentemente conceituadas como ideologias políticas (v.g., NAGEL, 1962; SEGAL; SPAETH, 2002; SUNSTEIN et al., 2004).

O teste empírico do modelo atitudinal requer a operacionalização de sua variável explicativa fundamental, qual seja, a atitude (predisposição) política dos juízes. Essa operacionalização ocorre por meio da classificação da ideologia pessoal do juiz como 
conservadora ou liberal. A explicação do comportamento judicial através do modelo atitudinal requer, portanto, a mensuração da ideologia dos juízes (RIBEIRO; ARGUELHES, 2013, p. 97).

Baum (2009) argumenta que, para um modelo atitudinal puro, em termos de escolha racional, juízes agiriam sinceramente (ou ingenuamente), ao invés de estrategicamente: eles atuariam diretamente em favor da realização das políticas públicas que melhor refletem suas preferências originais, sem qualquer cálculo referente às consequências de suas escolhas.

Para o modelo atitudinal,

[...] as decisões judiciais são melhor explicadas pelas preferências políticas trazidas para cada caso. A maioria dos estudos tentam testar a teoria inferindo as preferências políticas dos juízes a partir do partido político do Presidente que os indicou, embora reconheçam se tratar de uma proxy ainda em estado bruto. (POSNER, 2008, p. 20)

Variáveis partidárias são correlacionadas com os produtos das decisões judiciais e confrontadas com as posturas que se espera daqueles que tenham vínculo ao pensamento, ao conteúdo programático ou ao comportamento dos representantes de determinada legenda partidária.

Tais variáveis são utilizadas para classificar os julgadores segundo tendências ideológicas e tentar prever a probabilidade individual do conteúdo de cada voto dos integrantes de um órgão judicial, em casos de relevância política, estar, ou não, alinhado com as preferências do partido político responsável por sua indicação. (GOMES NETO, 2012, p. 109)

Epstein e Segal (2005), utilizando-se de um modelo atitudinal, encontraram evidências empíricas da importância do jogo político-partidário no procedimento de indicação dos Justices da Suprema Corte norte-americana e de sua posterior confirmação pelo respectivo Congresso, na maioria das vezes, caracterizados por disputadas entre os dois partidos políticos dominantes naquele sistema.

Por sua vez, Segal e Spaeth (2002) aplicaram o modelo atitudinal a um conjunto vasto de informações sobre os julgados da Suprema Corte norte-americana, encontrando substanciais evidências estatísticas de que a ideologia de cada Justice (apurada através de variáveis que categorizam suas atitudes) é determinante para o direcionamento de seus votos nos conflitos constitucionais a eles submetidos.

Noutro estudo atitudinal (SUNSTEIN et al., 2006), foi testada a influência de variáveis ideológicas sobre as decisões dos juízes federais norte-americanos, 
encontrando "notável evidência de uma correlação entre o partido político do Presidente responsável pela nomeação e os padrões judiciais de julgamento" (SUNSTEIN et al., 2006, p.147), na qual ficou claro que, na maioria dos temas políticos relevantes, os juízes indicados pelos Democratas decidem diferentemente daqueles indicados pelos Republicanos.

Serrano (2008) aplicou o modelo atitudinal a uma série de decisões do Tribunal Constitucional de Ecuador encontrando resultados que confirmam sua capacidade explicativa do processo decisório naquele Tribunal e demonstram que os votos nos conflitos constitucionais seriam reflexo de suas próprias preferências políticas anteriores (atitudes).

Quanto ao cenário brasileiro, Taylor (2008, p. 82-84) em estudo já mencionado, empregou variáveis atitudinais para verificar se a identidade partidária do Presidente que estava no poder quando a legislação foi aprovada afetaria o resultado quanto ao deferimento de liminares em ações diretas de inconstitucionalidade. Diferentemente de sua hipótese inicial, Taylor (2008, p. 86) verificou que os resultados de seu modelo não mostravam qualquer variação estatisticamente significante nas decisões judiciais, contra ou a favor de qualquer partido que se encontrasse no exercício da Presidência.

Os resultados de seu modelo sugerem que, para aquela unidade de análise, as atitudes dos Ministros do STF não teriam nenhuma influência sobre o deferimento de liminares em ADIns, o que aparentemente iria de encontro aos achados de outros estudos sobre os Tribunais Superiores na América Latina (HELMKE, 2002).

Oliveira (2012), utilizando a composição do tribunal (divisão em sete períodos históricos, entre 1999 e 2006, nos quais ocorreu variação na composição do Tribunal, entendida como a distribuição percentual dos membros quanto à sua origem nas carreiras jurídicas - advogado, ministério público ou juiz de carreira) como um proxy de variável atitudinal, ou seja, como um indicador de perfil ideológico, notou que ela exercia um grande peso no julgamento de mérito favorável das ações diretas de inconstitucionalidade, havendo alteração no resultado conforme ocorria alterações na referida distribuição percentual.

Em outro estudo atitudinal sobre o nosso Supremo Tribunal Federal, Jaloretto e Mueller (2011), por sua vez, concluíram não haver evidência empírica suficiente que sustente que o método constitucional de escolha dos ministros do STF, caracterizado pela indicação presidencial, implique necessária e efetivamente numa influência das preferências do Poder Executivo sobre as preferências materializadas nas decisões futuras a serem tomadas pelo Judiciário.

Tal modelo (atitudinal), em suma, dá especial destaque ao rompimento com o mito da neutralidade judicial, a partir da busca por evidências de natureza empírica, testando a hipótese de que os juízes, embora institucionalmente independentes e formalmente imparciais, seriam influenciados em seu processo decisório por fatores adquiridos ao longo de sua trajetória pessoal, como suas preferências, de suas ideologias, e de seus preconceitos, em suma, suas atitudes. 
A perspectiva política enxerga o processo decisório judicial como um processo no qual fatores extralegais, entre os quais as atitudes dos juízes e o papel das ideologias, são a influência primária nas decisões judiciais (TARR, 2012, p. 248).

A opção por este modelo concebe o Judiciário, não apenas como uma instituição, mas como "uma coleção de indivíduos que estão à procura de realizar suas preferências políticas individuais", a partir da ideia de que seriam menos suscetíveis às investidas dos demais agentes, ao contrário do Legislativo ou do Executivo, a partir de condições específicas de independência e de autonomia (GILMAN; CLAYTON, 1999, p. 01).

Por exemplo, Arguelhes e Ribeiro (2016) sugerem que as sucessivas mudanças de composição do Supremo Tribunal Federal oferecem uma interessante variável (proxy) para a compreensão das dinâmicas do Tribunal, notadamente quanto às mudanças de entendimento acerca de determinados temas, analisadas ao longo de uma série temporal, assumindo a ocorrência de variação decisória coletiva, a partir da sucessiva variação na soma de preferências individuais dos órgãos julgadores.

A partir de então, construíram-se modelos nos quais os agentes escolhiam comportamentos, em dadas circunstâncias, caracterizando atitudes, em relação às quais poderiam ser traçados perfis individuais, v.g. perfis dos julgadores, que, submetidos à verificação empírica de repetições e padrões, poderiam formar perfis da maioria e da minoria, contribuindo para uma relativa condição de previsibilidade das posições (julgamentos, votos) que seriam tomadas, diante da atitude esperada (GOMES NETO, 2012, p.110).

Espera-se, na origem do modelo, originalmente aplicado ao sistema políticopartidário norte-americano, que juízes indicados por Presidentes Democratas sejam simpáticos a uma agenda liberal e a temas sociais, como direitos trabalhistas, sindicatos e consumidores; em sentido oposto, espera-se dos juízes indicados pelos Republicanos sejam contrários a tais temas e favoráveis a outros, como à não intervenção estatal na economia e à relativização de direitos sociais (POSNER, 2008; SCHUBERT, 1958).

Para Arguelhes (2014), mirando o cenário institucional brasileiro, as preferências dos Ministros do STF sobre "como exercer o poder de que dispõem e de quanto poder deveriam dispor podem interagir com as variáveis exógenas para gerar mais ou menos participação do STF na vida política nacional".

Em suma, pesquisas empíricas que utilizem o modelo atitudinal assumem que as preferências refletidas (expressa ou tacitamente) nas decisões judiciais presentes refletem aspectos das preferências agregadas pelo julgador ao longo de sua 
trajetória, ou seja, o que se decide hoje seria (total ou parcialmente) produto das vivências experimentadas no passado, capazes de influir na construção das preferências individuais acerca de cada tema.

Noutro sentido, os modelos estratégicos analisam a variação das preferências judiciais a partir do teste de um cálculo decisório que considera predominantemente as consequências futuras do julgamento.

Quadro 2-Modelo Atitudinal

\begin{tabular}{|c|c|c|c|c|}
\hline Modelo & Hipóteses & Variáveis mais utilizadas & Referências & Ferramentas de pesquisa frequentes \\
\hline
\end{tabular}

\section{O MODELO ESTRATÉGICO}

Por sua vez, os modelos estratégicos de decisão judicial antecipam que os juízes possuem um conjunto de preferências (tal como sugerido pelo modelo atitudinal), mas buscam estas preferências de uma maneira sofisticada, prudente, indireta, ou seja, estratégica, e não de forma sincera e direta.

Sob as condições deste modelo, um juiz orientado politicamente deve estar preparado para sopesar os custos e benefícios relativos que irão resultar de suas decisões formais e de seus esforços informais de influência. Deve ele considerar que, em virtude de suas decisões, alguns litigantes, bem como alguns interesses sociais, poderão sofrer perdas a partir de suas decisões, levando-a a pagar pelos custos que sustentam tais interesses. [...] Desde que, em matérias importantes, alguns ou a maioria de seus colegas estão aptos a ter fortes sentimentos individuais, deve estar preparado para pagar os custos de suas decisões - custos computados em tempo e 
energia, mas também em credibilidade, prestígio e em capital de barganha. (MURPHY, 1964, p. 35)

Posto isto, os magistrados sofreriam constrangimentos nas suas preferências (v.g., por políticas públicas), através da influência de outros atores políticos (v.g., as preferências dos demais Poderes políticos), de instituições externas ao Tribunal (v.g., normas de remoção de juízes ou a existência de Judicial Councils, a exemplo do nosso Conselho Nacional de Justiça) e de instituições internas do Tribunal (v.g., ordem de votação, pedidos de vista e vinculação a precedentes), na hora de tomar decisões diante de um litígio que lhes foi submetido (EPSTEIN; KNIGHT, 1998).

Optamos por uma abordagem que ressalta uma importante contribuição de análises estratégicas do direito e das instituições jurídicas: elas têm forçado os estudiosos (para não mencionar advogados e juízes) a pensar sobre a interdependente - ou seja, estratégica - natureza das decisões judiciais. Em análises estratégicas, em outras palavras, os juízes não tomam decisões em um vácuo, mas sim levam em conta as preferências e ações susceptíveis de outros atores relevantes, incluindo (a) os seus colegas, (b) seus superiores judiciais, e (c) membros dos outros ramos do governo. (EPSTEIN; JACOBI, 2010, p. 342)

O modelo estratégico procura identificar os vários interesses conflitantes enfrentados pelos juízes quando elaboram suas decisões, pois, em essência, procura explorar o papel que a política desempenha no processo decisório judicial (SPILLER; GELY, 2008). Num modelo estratégico puro, juízes procuram produzir boas políticas públicas, mas eles definem boas políticas públicas em função das respectivas consequências para sua Corte e para o Estado como um todo (BAUM, 2009, p. 05-06).

É pressuposto do modelo estratégico a ideia de que os juízes constrangem suas preferências pessoais a partir de racionalidades estratégicas sobre as prováveis reações de outros atores (EPSTEIN; KNIGHT, 1998; BOWIE; SONGER, 2009).

Se o compromisso com uma visão de política desejável pode motivar ação política em outras arenas, como a atividade de grupos de interesse [...] certamente um compromisso semelhante pode influenciar as escolhas dos juízes. Além disso, os juízes que agem estrategicamente em seus objetivos de política podem desfrutar a sensação de que eles estão ganhando vitórias e exercendo influência. (BAUM, 2009, p. 10) 
Em contraste com os modelos atitudinais, os quais arguem que os juízes decidem de maneira sincera - fundamentando os resultados que melhor refletem suas preferências pessoais e/ou ideológicas - juízes que decidem estrategicamente consideram as potenciais ações de outros atores e podem modificar sua conduta em resposta às prováveis reações dos outros.

[...] [E]sta perspectiva destaca a importância do desejo dos juízes por obter a aprovação e o respeito do público interno e externo aos Tribunais onde eles servem. O desejo de aprovação pelos outros juízes, por contatos sociais próximos, pela academia, formadores de opinião e outras influências que os juízes possam considerar no seu comportamento dentro e fora dos Tribunais. (TARR, 2012, p. 249)

Para este modelo, as decisões dos juízes não são frutos de imaginados atores neutros (os autômatos aplicadores de preceitos legais imaginados pelos modelos legalistas puros), nem tampouco consequências puras de suas preferências políticas (atitudes), mas uma combinação destes fatores com as preocupações que os julgadores possuem em relação às expectativas de outros atores.

Surge, pois, o problema, relacionado à variação nos processos decisórios, a ser investigado pelos pesquisadores: identificar quando e como irão os juízes, de maneira estratégica, modificar seu comportamento na hora de decidir os conflitos politicamente relevantes (BOWIE; SONGER, 2009).

Conforme a lição de Falcão (2015, p. 93), o Supremo seria um tribunal político - e por isso estratégico - não apenas porque concordaria ou discordaria do Executivo ou do Congresso, mas antes porque controlaria o tempo de concordar ou discordar.

\begin{abstract}
O modelo estratégico do comportamento judicial (também chamado de modelo político-positivo) toma por ponto de partida a ideia de que os juízes nem sempre tomariam determinada decisão se não estivessem preocupados com a reação que seus votos poderiam causar na opinião de outros juízes, nos legisladores ou no próprio público, organizando a análise da estratégia política através dos pontos de pressão dos grupos de interesses, mediante o emprego dos métodos da teoria dos jogos, e/ou levando em consideração embates históricos entre os Judiciários e os demais Poderes de governo (GOMES NETO, 2012, p. 113).
\end{abstract}

Para a concepção estratégica, os magistrados não decidem sempre da forma como seria esperada deles, em virtude de haver uma preocupação com as expectativas e as reações dos outros atores e de outras instituições: o que o juiz irá 
decidir dependerá, em grau considerável, das preferências das outras pessoas que participam da "cadeia de comando" (POSNER, 2008).

Assim, comportando-se de forma estratégica, espera-se que o julgador decida o conflito atento às expectativas dos demais atores políticos envolvidos na questão controversa, num determinado cenário de tempo e de espaço. “Um magistrado orientado politicamente pode ter que fazer avaliações frequentes e cuidadosas das estruturas de poder, uma vez que estas são dinâmicas e não estáticas" (MURPHY, 1964, p. 31).

Em trabalho seminal sobre o comportamento judicial estratégico, Dahl (1957) mostrou como a variação das sucessivas maiorias legislativas no Congresso estadunidense, bem como as características das coalizões, ao longo do tempo, tinham influência no comportamento individual do Justices da Suprema Corte norte-americana

De acordo com Epstein e Knight (1998), variáveis estratégicas explicam que as coalizões de governo existentes no momento em que o caso é submetido ao Poder Judiciário influenciam no direcionamento das decisões a serem tomadas pelo Justice da Suprema Corte norte-americana.

Neste mesmo sentido, Caldeira et al. (1999), aplicando modelos estratégicos, encontraram evidências de que a aceitação de casos para serem analisados pelos magistrados da Suprema Corte norte-americana, ou seja, a concessão do writ of certoriari, depende, em grande parte, da percepção que os julgadores possuem a respeito das consequências daquele caso em particular para a sociedade.

Por sua vez, Gely e Spiller (1992) sustentam com base em modelos estratégicos que, em determinados leading cases, o julgamento colegiado realizado no ambiente da Suprema Corte norte-americana tinha sido influenciado pela antecipação das reações que o Congresso poderia ter em relação ao teor das decisões.

Amaral-Garcia et al. (2009) procuraram mensurar a influência de fatores jurídicos, estratégicos e atitudinais sobre as decisões do Tribunal Constitucional Português, de modo a testar o grau de independência dos juízes integrantes de uma Corte Constitucional de inspiração kelseniana, encontrando significativa influência de fatores econômicos como desemprego, crescimento do PIB e inflação sobre a variação das decisões no âmbito do controle concentrado de constitucionalidade.

Utilizando o modelo estratégico, Epstein et al. (2011) pesquisaram decisões dos Tribunais Federais norte-americanos e encontraram dados sobre o fenômeno que se denominou aversão à divergência, onde o crescimento do número de decisões por unanimidade foi explicada a partir de um cenário em que a divergência impunha custos institucionais indesejáveis aos juízes não dissidentes e ganhos irrelevantes aos juízes que tentavam alterar a trajetória dos precedentes ou marcar seu posicionamento em determinado caso.

O modelo estratégico também foi utilizado por McNollgast (1994) para demonstrar como uma forte coalizão política, permitindo o fortalecimento da atuação dos órgãos judiciais hierarquicamente inferiores, poderia levar uma 
Suprema Corte a alterar seu posicionamento sobre uma determinada matéria, diante da preocupação com a expansão exponencial do número de decisões divergentes.

Em recente trabalho, Epstein e Knight (2013) apresentam um novo e sofisticado modelo de análise do processo decisório judicial, o qual se apresenta de forma substitutiva às explicações atitudinais e estratégicas puras: introduzem as motivações pessoais dos juízes como fator relevante (quiçá preponderante) às tomadas de decisão em complemento às variáveis ideológicas e aos fatores tipicamente jurídicos. Argumentam que os juízes decidem, uma vez que alocam seu tempo entre atividades tipicamente judiciais, trabalho não-judicial (conferências, ensino etc.) e lazer, e consideradas as restrições de tempo, procurando maximizar suas preferências sobre um conjunto de fatores pessoais (a maioria dos quais também têm implicações para objetivos ideológicos e jurídicos): 1) satisfação com o trabalho; 2) satisfações externas; 3) tempo livre; 4) vencimentos; e 5) carreira.

Novamente quanto ao caso brasileiro, analisando variáveis estratégicas em seu estudo sobre a concessão de liminares pelo Supremo Tribunal Federal em ações diretas de inconstitucionalidade, Taylor (2008) verificou que alguns atores (Requerentes) possuíam maior chance de obter decisões favoráveis que outros, havendo uma grande variação de chances entre aqueles que propuseram Adins, apontando na direção esperada pela literatura que trata do modelo estratégico.

Por sua vez, Oliveira (2012), utilizando um modelo estratégico para analisar o julgamento de mérito das ações diretas de constitucionalidade, encontrou evidências empíricas estatisticamente significantes de que variáveis estratégicas, como os o atores políticos que propõem as ações (requerentes), o momento em que o caso vai a julgamento (timing) e as dinâmicas internas do Supremo Tribunal Federal (relatores) influenciavam nos resultados dos julgamentos.

Em relevante trabalho, Arguelhes e Hartmann (2007), através de dados descritivos do comportamento do Supremo Tribunal Federal, demonstram que o instrumento institucional dos pedidos de vista é utilizado estrategicamente pelos Ministros como mecanismo de timing control para remoção ou para posterior inclusão de conflitos na agenda de julgamento, evitando os custos do julgamento imediato.

Carvalho (2016), em sua tese de doutorado sobre as dinâmicas das arguições de suspeição no âmbito do STF, utiliza um modelo estratégico para identificar que os respectivos Ministros decidem de forma elástica sobre o que seria a imparcialidade judicial, preservando a imagem de todos os membros e do Tribunal Supremo como instituição.

Já o estudo sobre a apreciação dos pedidos de suspensão pelos sucessivos Ministros Presidentes do STF encontrou, através de um modelo composto (estratégico e atitudinal), evidências significativas da influência conjunta de variáveis atitudinais (identidade partidária do Ministro do STF - apurada a partir do 
partido político responsável por sua indicação) e de variáveis estratégicas (tempo e condições econômicas) sobre a possibilidade deferimento da suspensão requerida (GOMES NETO, 2015).

Sob as condições deste modelo [o estratégico], um juiz orientado politicamente deve estar preparado para sopesar os custos e benefícios relativos que irão resultar de suas decisões formais e não apenas como uma resposta a suas ideologias pessoais ou a uma jurisprudência apolítica (EPSTEIN; KNIGHT, 1998, p. xiii).

Para Epstein e Walker (2007, p.41) as abordagens estratégicas sobre o processo decisório judicial estão alicerçadas nas seguintes proposições: 1) embora os juízes possam ser inclinados a buscar os direcionamentos políticos fixados nas leis, não são atores livres de constrangimentos que simplesmente buscam cumprir "a vontade da lei" ou decidir conforme suas atitudes ideológicas; 2) juízes são atores estratégicos que percebem que habilidade de alcançar seus objetivos depende da consideração das preferências de outros atores relevantes, as expectativas deles e o contexto institucional no qual atuam.

Quadro 3 - Modelo Estratégico

\begin{tabular}{|c|c|c|c|c|}
\hline Modelo & Hipóteses & Variáveis mais utilizadas & Referências & Ferramentas de pesquisa frequentes \\
\hline
\end{tabular}

Fonte: Elaboração do autor.

Taylor (2008, p.158), por sua vez, adverte acerca do sistema judiciário brasileiro:

[...] dado que os juízes não são capazes [a princípio] de escolher as matérias relacionadas às políticas públicas que lhe serão submetidas ou as partes a que deverão responder, os padrões de deliberação política dos Tribunais são muito mais amplos que as atitudes dos juízes ou suas estratégias, isoladamente, poderiam predizer. 
Para este modelo, constrangimentos externos ao órgão judicial podem ainda gerar incentivos institucionais para que os juízes se comportem de maneira estratégica, ponderando os custos que suportarão em virtude dos resultados de suas decisões e respondendo, positiva ou negativamente, às expectativas, v.g., dos litigantes, da opinião pública, dos interesses de grupos de pressão e da academia (MURPHY, 1964).

\section{CONCLUSÃo}

Na tarefa de explicar empiricamente como são construídas as decisões judiciais, o pesquisador encontra amparo nas ferramentas metodológicas inerentes aos diversos modelos formais explicativos, dentro os quais, predominantemente, os modelos legalista, atitudinal e estratégico.

Modelos exercem o papel de realizar a interseção entre a teoria pura e os instrumentos metodológicos, sistematizando as informações colhidas e testando empiricamente hipóteses relacionadas ao objeto de estudo, permitindo que estudos empíricos possam alcançar conhecimento acerca de relações de causalidade entre diversas variáveis e o fenômeno factual que se pretende entender. In casu, explicar as razões pelas quais os juízes decidem desta ou daquela forma os conflitos que the são apresentados, especialmente aqueles cujas consequências afetam as arenas de deliberação política, as políticas públicas e as instituições representativas.

Como visto acima, os três modelos formais compilados neste trabalho oferecem explicações testáveis sobre o comportamento judicial, instruídos por variáveis que relacionam a variação do resultado das decisões individuais ou coletivas a categorias jurídicas (legalista), a características prévias do julgador (atitudinal) e/ou à influência de outros atores ou de fatores externos ao Tribunal ou ao ambiente decisório (estratégico).

Dessa maneira, a compreensão dos elementos que determinam o processo decisório judicial demanda não apenas a utilização dos três modelos, visando a identificar cada nuance presente na decisão, como, muitas vezes, a complexidade institucional levará à aplicação conjunta, e não isolada, destes modelos e o teste de suas respectivas variáveis, isoladas ou sob interação, para a ampliação de sua capacidade preditiva acerca do processo decisório judicial.

A complexidade do processo de construção dos julgamentos oferece campo fértil à união entre hipóteses apresentadas nos valorosos ensaios presentes na literatura constitucional e processual e os referidos modelos formais, de modo a apresentar sólidas respostas aos problemas de pesquisa sobre o comportamento judicial, empiricamente fundamentadas.

\section{REFERÊNCIAS}


AMARAL-GARCIA, S.; GAROUPA, N.; GREMBI, V. Judicial independence and party politics in the Kelsenian Constitutional Courts: The case of Portugal. Journal of Empirical Legal Studies, v. 6, n. 2, 2009, p. 381-404.

ARGUELHES, D. W. Poder não é querer: preferências restritivas e redesenho institucional no Supremo Tribunal Federal pós-democratização. Universitas JUS, v. 25, n. 1,2014 , p. 25-45.

ARGUELHES, D. W.; RIBEIRO, L. M. Criatura e/ou criador: transformações do Supremo Tribunal Federal sob a Constituição de 1988. Revista Direito GV, v. 12, n. 2, 2016, p. 405-440.

ARGUELHES, D. W.; HARTMANN, I. A. Timing Control without Docket Control: How Individual Justices Shape the Brazilian Supreme Court's Agenda. Journal of Law and Courts, v. 5, n. 1, 2017, p. 105-140.

BAUM, L. Judges and their audiences: A perspective on judicial behavior. Princeton University Press, 2009.

BOBBIO, N. Era dos direitos. Elsevier Brasil, 2004.

BOWIE, J. B.; SONGER, D. R. Assessing the Applicability of Strategic Theory to Explain Decision Making on the Courts of Appeals. Political Research Quarterly, v. 62 , n. 2, 2009, p. 393-407.

CALDEIRA, G. A.; WRIGHT, J. R.; ZORN, C. J. Sophisticated voting and gatekeeping in the Supreme Court. Journal of Law, Economics, and Organization, v. 15, n. 3, 1999, p. 549-572.

CARVALHO, A. D. Z. de. Imagens da imparcialidade: entre o discurso constitucional e a prática judicial. 2016. $311 \mathrm{f}$. Tese [Doutorado em Direito] Universidade de Brasília, Brasília, 2016.

CARVALHO, E. R. de. Em busca da judicialização da política no Brasil: apontamentos para uma nova abordagem. Revista de Sociologia e Política, v. 23, 2004, p. 127-13.

CLAYTON, C. W. The Supreme Court and Political Jurisprudence: New and Old institutionalisms. In: CLAYTON, Cornell W.; GILLMAN, Howard (Ed.). Supreme 
Court Decision-Making: new institutionalist approaches. Chicago: University of Chicago Press, 1999.

COOK, B. B. A critique of Supreme Court's 1982 agenda: alternatives to the NYU legal model. The Justice System Journal, v. 17, n. 2, 1994, p. 135-151.

DAHL, R. A. (1957). Decision-making in a democracy: The Supreme Court as a national policy-maker. Journal of Public Law, v6, 1957.

DAHL, R. A. Polyarchy: Participation and opposition. Yale University Press, 1973.

ELSTER, J. Ulysses and the sirens: Studies in rationality and irrationality. vol. 1. Cambridge: Cambridge University Press, 1979.

ELSTER, J. Ulysses unbound: Studies in rationality, precommitment, and constraints. Cambridge University Press, 2000.

EPSTEIN, L.; KNIGHT, J. The Choices Justices Make. Washington, D. C.: Congressional Quarterly, 1998.

EPSTEIN, L.; SEGAL, J. A. Advice And Consent: The Politics Of Judicial Appointments. Oxford: Oxford University Press, 2005.

EPSTEIN, L.; WALKER, T. G. Constitutional Law for a Changing America: Institutional Powers and Constraints. Washington, D.C.: Congressional Quarterly Press, 2007.

EPSTEIN, L.; JACOBI, T. The strategic analysis of judicial decisions. Annual Review of Law and Social Science, v. 6, 2010, p. 341-358.

EPSTEIN, L.; LANDES, W. M.; POSNER, R. A. Why (and When) Judges Dissent: A Theoretical and Empirical Analysis. Journal of Legal Analysis, v. 3, n. 1, 2011, p. 101-137.

EPSTEIN, L.; KNIGHT, J. Reconsidering judicial preferences. Political Science, v. 16, n. 1, 2013.

EPSTEIN, L.; MARTIN, A. D. An introduction to empirical legal research. Oxford University Press, 2014. 
ESTREICHER, S.; SEXTON, J. Redefining the Supreme Court's Role: A Theory of Managing the Federal Judicial System. New Haven: Yale University Press, 1986.

FALCÃO, J. O Supremo: compreenda o poder, as razões e as consequências das decisões da mais alta Corte do Judiciário no Brasil. Rio de Janeiro: Fundação Getúlio Vargas, 2015.

GELY, R.; SPILLER, P. T. The political economy of Supreme Court constitutional decisions: the case of Roosevelt's court-packing plan. International Review Of Law And Economics, v. 12, n. 1, 1992, p. 45-67.

GILLMAN, H. What's Law Got to Do with It? Judicial Behavioralists Test the "Legal Model" of Judicial Decision Making. Law \& Social Inquiry, v. 26, n. 2, 2001, p. 465-504.

GILLMAN, H.; CLAYTON, C. W. Beyond Judicial Attitudes: Institutional approaches to Supreme Court Decision-Making. In: CLAYTON, Cornell W.; GILLMAN, Howard (Ed.). Supreme Court Decision-Making: new institucionalist approaches. Chicago: University of Chicago Press, 1999.

GINSBURG, T. Judicial review in new democracies: Constitutional courts in Asian cases. Cambridge University Press, 2013.

GOMES NETO, J. M. W. As várias faces de um leviathan togado: um espectro das abordagens teóricas em ciência política acerca do fenômeno da judicial politics. Mnemonise Revista, v. 3, 2012, p. 107-120.

GOMES NETO, J. M. W. Pretores estratégicos: por que o Judiciário decide a favor do Poder Executivo e contra suas próprias decisões?: análise empírica dos pedidos de suspensão apresentados ao STF (1993-2012). 2015. 98 fls. Tese (Doutorado em Ciência Política), Universidade Federal de Pernambuco, Recife, 2015.

HECKMAN, J. J. The scientific model of causality. Sociological Methodology, v. 35, 2005, p. 01-97. 
HEISE, M. Past, Present, and Future of Empirical Legal Scholarship: Judicial Decision-Making and the New Empiricism. The University of Illinois Law Review, 2002, p. 819-850.

HELMKE, G. The logic of strategic defection: Court-executive relations in Argentina under dictatorship and democracy. American Political Science Review, v. 96, v. 02, 2002, p. 291-303.

HIRSCH, R. Toward Juristocracy. Cambridge: Harvard University Press, 2004.

JALORETTO, M. F. ; MUELLER, B. P. M. O procedimento de escolha dos Ministros do Supremo Tribunal Federal - Uma análise empírica. EALR, v. 2, n. 1, 2011, p. 170-187.

KING, G.; KEOHANE, R. O.; VERBA, S. The importance of research design in political science. American Political Science Review, v. 89, n. 2, 1995, p. 475-481.

McNOLLGAST. (1994). Politics and the courts: A positive theory of judicial doctrine and the rule of law. South California Law Review, 68, 1631.

MALTZMAN, F. et al. Strategy and Judicial Choice: New Institutionalist Approaches to Supreme Court Decision-Making. In: CLAYTON, Cornell W.; GILLMAN, Howard (Ed.). Supreme Court Decision-Making: new institutionalist approaches. Chicago: University of Chicago Press, 1999.

MURPHY, W. Elements of judicial strategy. Chicago: University of Chicago Press, 1999.

MURPHY, W. et al. Courts, Judges \& Politics. An introduction to the judicial process. New York: Mc Graw Hill, 2002.

NAGEL, S. S. Testing Relations between Judicial Characteristics and Judicial Decision. The Western Political Quarterly, v. 15, n. 3, 1962, p. 425-437.

NAGEL, S.; NEEF, M. Models Of Judicial Decision-Making. In: JOHNSON, G. W. American Political Science Research Guide, v.1. New York: IFI/Plenum Data Company, 1977. 
OLIVEIRA, F. L. SUPREMO RELATOR: Processo decisório e mudanças na composição do STF nos governos FHC e LULA. Revista Brasileira de Ciências Sociais, v. 27, n. 80, 2012, p. 89-115.

POSNER, R. A. Meaning of Judicial Self-Restraint, The Indiana Law Journal, v. 59, n. 1, 1983.

POSNER, R. A. How judges think. Cambridge: Harvard University Press, 2008.

PRITCHETT, C. H. Public Law and Judicial Behavior. The Journal of Politics, v. 30, n. 2, 1968, p. 480-509.

RIBEIRO, L. M.; ARGUELHES, D. W. Preferências, Estratégias e Motivações: Pressupostos institucionais de teorias sobre comportamento judicial e sua transposição para o caso brasileiro. Revista Direito e Práxis, v. 4, n. 7, 2013.

SCHUBERT, G. A. The Study of Judicial Decision-Making as an Aspect of Political Behavior. The American Political Science Review, v. 52, n. 4, 1958, p. 1007-1025.

SEGAL, J. A. Predicting Supreme Court cases probabilistically: The search and seizure cases, 1962-1981. American Political Science Review, v. 78, n. 4, 1984, p. 891-900.

SEGAL, J. A.; EPSTEIN, L.; CAMERON, C. M.; SPAETH, H. J. Ideological Values and the Votes of U.S. Supreme Court Justices Revisited. The Journal of Politics, v. 57, n. 3, 1995, p. 812-823.

SEGAL, J. A.; SPAETH, H. J. The Supreme Court and the attitudinal model revisited. New York: Cambridge University Press, 2002.

SEGAL, Jeffrey A. Judicial Behavior. In: WHITTINGTON, K. E.; KELEMEN, R. D.; CALDEIRA, G. A (Eds.) The Oxford Handbook of Law and Politics. Oxford: Oxford University Press, 2008.

SERRANO, S. B. Las preferencias ideológicas y políticas judiciales: un modelo actitudinal sobre el voto en el tribunal constitucional de ecuador. América Latina Hoy, v. 49, 2008, p. 157-177. 
SPILLER, P.; GELY, R. Strategic judicial decision-making. In: WHITTINGTON, K. et al. (org.). The Oxford Handbook of Law and Politics. Oxford, Oxford University Press, 2008.

SUNSTEIN, C. R.; SCHKADE, D.; ELLMAN, L. M. Ideological voting on federal courts of appeals: A preliminary investigation. Virginia Law Review, 2004, p. 301-354.

SUNSTEIN, C. R. et al. Are judges political? An empirical analysis of the Federal Judiciary. Washington DC: The Brookings Institution, 2006.

TARR, G. (2012). Judicial process and judicial policymaking. Cengage Learning.

TATE, C. N. Why the expansion of Judicial Power? In: VALLINDER, T.;

TATE, C. N. The Global Expansion of Judicial Power: The Judicialization of Politics. New York: New York University Press, 1995.

TAYLOR, M. Citizens against the state: the riddle of high impact, low functionality courts in Brazil. Brazilian Journal of Political Economy, v.25, n. 4 2005.

TAYLOR, M. M. Judging policy: Courts and Policy Reform in Democratic Brazil. Stanford: Stanford University Press, 2008.

TAYLOR, M. M.; DA ROS, L. Os partidos dentro e fora do poder: judicialização como resultado contingente da estratégia política. Revista Brasileira de Ciências Sociais, v. 51, n. 4, 2008, p. 825-864.

VALLINDER, T. When the Courts Go Marching In: VALLINDER, T.; TATE, C. N. The Global Expansion of Judicial Power: The Judicialization of Politics. New York: New York University Press, 1995.

VALLINDER, T.; TATE, C. N. The Global Expansion of Judicial Power: The Judicialization of Politics. New York: New York University Press, 1995.

VIANNA, L. W. Judicialização da política. In: AVRITZER, Leonardo et al. (orgs.). Dimensões políticas da justiça. Rio de Janeiro: Civilização Brasileira, 2003. 
VIANNA, L. W. et al. A judicialização da política e das relações sociais no Brasil. Rio de Janeiro: Revan, 1999.

VIANNA, L. W.; BURGOS, M. B.; SALLES, P. M. Dezessete anos de judicialização da política. Tempo social, v. 19, n. 2, 1997, p. 39-85.

WEINGAST, B. R. The political foundations of democracy and the rule of the law. American political science review, v. 91, n. 2, 1997, p. 245-263. 